\title{
Effects of striatal transplantation of cells transfected with GDNF gene without pre- and pro-regions in mouse model of Parkinson's disease
}

\author{
A. Revishchin ${ }^{1,2}$, L. Moiseenko ${ }^{3,5}$, N. Kust $^{1,2}$, N. Bazhenova ${ }^{3,6}$, P. Teslia ${ }^{1}$, D. Panteleev ${ }^{1}$, V. Kovalzon ${ }^{4 \dagger}$ \\ and G. Pavlova ${ }^{1,2^{*}+}$
}

\begin{abstract}
Background: Previously, we have shown that transgenic cells bearing the GDNF gene with deleted pre- and proregions ( $m G D N F$ ) can release transgenic GDNF. The medium conditioned by transgenic cells with mGDNF induced axonal growth in rat embryonic spinal ganglion in vitro. Here we demonstrate a neurotrophic effect of mGDNF on PC12 cells in vitro as well as its neuroprotective effect on dopaminergic neurons in the substantia nigra pars compacta in vivo as indicated by improved motor coordination and sleep-wakefulness cycle in the MPTP mouse model of Parkinson's disease.

Results: HEK293 cells were transfected with a vector encoding an isoform of the human GDNF gene with deleted pre- and pro-regions (mGDNF). This factor in the medium conditioned by the transfected cells was shown to induce axonal growth in PC12 cells. The early Parkinson's disease model was established by injection of the dopaminergic pro-neurotoxin 1-methyl-4-phenyl-1,2,3,6-tetrahydropyridine (MPTP) into C57BI/6 mice. Transgenic HEK293/mGDNF/ GFP cells were transplanted into the striatum (caudate-putamen) of experimental mice. The sleep-wakefulness cycle was studied by continuous EEG and motor activity monitoring 1 and 2 weeks after MPTP injection. After the experiment, the motor coordination of experimental animals was evaluated in the rotarod test, and dopaminergic neurons in the substantia nigra pars compacta were counted in cross-sections of the midbrain. MPTP administration lowered the number of tyrosine hydroxylase immunopositive cells in the substantia nigra pars compacta, decreased motor coordination, and increased the total wake time during the dark period. The transplantation of HEK293/mGDNF cells into the caudate-putamen 3 days prior to MPTP injection smoothed these effects, while the control transplantation of HEK293 cells showed no notable impact.

Conclusions: Transplantation of transgenic cells with the GDNF gene lacking the pre- and pro-sequences can protect dopaminergic neurons in the mouse midbrain from the subsequent administration of the pro-neurotoxin MPTP, which is confirmed by polysomnographic, behavioral and histochemical data. Hence it is released from transfected cells and preserves the differentiation activity and neuroprotective properties.
\end{abstract}

Keywords: Neurotrophic factor, GDNF, Parkinson's disease, Sleep-wakefulness cycle, Substantia nigra

\footnotetext{
*Correspondence: Ikorochkin@mail.ru

${ }^{\dagger} \mathrm{V}$. Kovalzon and G. Pavlova contributed equally to this work

${ }^{1}$ Laboratory of Neurogenetic and Developmental Genetic, Institute

of Gene Biology, Russian Academy of Sciences, Vavilova Str., 34/5,

Moscow, Russia 119334

Full list of author information is available at the end of the article
} 


\section{Background}

Glial cell line-derived neurotrophic factor (GDNF) promotes the survival and differentiation of neurons and glial cells [1-3]. This GDNF activity can be useful in the treatment of neuronal degeneration and loss of differentiation typical for a number of neurodegenerative diseases. GDNF has a pronounced neuroprotective effect on dopaminergic neurons and spinal motoneurons [4] and induces axonal growth [5].

GDNF is expressed in both neurons and astrocytes $[6,7]$. It was proposed that elevated GDNF synthesis in astrocytes promotes neuronal survival after ischemic [8] and excitotoxic damage [6]. The importance of GDNF for the maintenance of neuronal viability is also confirmed by the transplantability of cerebral tissues in GDNF-deficient mice. Dopaminergic neurons of $\mathrm{GDNF}^{-1-}$ mouse embryos transplanted into the dorsal striatum of wild type mice cannot survive and innervate the striatum after MPTP-induced degeneration of their endogenous dopaminergic neurons [9]. The significance of GDNF as a neurotrophic factor was also confirmed by a sharp reduction of dopaminergic sprouting in the injured striatum after antisense inhibition of GDNF expression [10]. Protective effect of GDNF on dopaminergic neurons was demonstrated in several models of Parkinson's disease [11-15].

The human GDNF gene contains six exons and generates five isoforms [16]. The encoded GDNF mRNAs include the full-length pre- $(\alpha)$ pro-GDNF transcript and the pre-( $\beta$ )pro-GDNF, the latter is shorter by $78 \mathrm{bp}$ in region of the pro-domain. The protein encoded by pre- $(\alpha)$ pro-GDNF is released from the cell via the conventional pathway through the Golgi apparatus [17]. At the same time, the release of the shorter protein encoded by pre-( $\beta$ )pro-GDNF is largely mediated by secretogranin II and Rab3A-positive vesicles and, thus, bypasses the Golgi apparatus. Kust et al. [1] demonstrated that the deletion of the pre- and pro-regions of the GDNF gene does not affect the transgenic factor release from transfected cells. Moreover, the deletion of both pre- and proregions enhances the trophic activity of GDNF. Spinal ganglia cultured in the presence of medium conditioned by cells transfected with mGDNF demonstrated active growth of $\beta$-3-tubulin-positive axons by day 4 of culture [1].

Here, we studied the effect of transgenic mGDNF encoded by the GDNF gene with deleted pre- and proregions in PC12 cells in vitro. Then, the effect of mGDNFproducer cells on the survival of dopaminergic neurons in the mouse substantia nigra was evaluated in vivo using the conventional 1-methyl-4-phenyl-1,2,3,6-tetrahydropyridine (MPTP) model of Parkinson's disease [18]. This model was used repeatedly for the study of neuroprotective substances, neurotoxin being administrated in many cases after the neuroprotectors $[16,19]$. The MPTP effect depends on the dose and administration mode. Here, we used a single subcutaneous administration of $40 \mathrm{mg} / \mathrm{kg}$ MPTP, which induces an early clinical stage of Parkinson's disease [19].

The effect of mGDNF-producing transgenic cells was evaluated using the rotarod test for motor coordination of experimental mice [20]. In addition, we implemented a test evaluating early abnormalities of brain function through the changes in the sleep-wakefulness cycle. Parkinson's disease is accompanied by a wide range of sleepwakefulness cycle abnormalities observed in 45-92\% patients. In particular, many patients demonstrate prolonged nighttime awakenings and reduced NREM and REM sleep [21, 22]. In the MPTP model of early Parkinson's disease, experimental mice also demonstrate increased activity and reduced NREM and REM sleep at nighttime [23], i.e., in the same period of pineal melatonin production when the corresponding sleep disorders are observed in patients [24]. So, this model is adequate for studying the effects of various biochemical factors in early Parkinson's disease.

In this work it was demonstrated that transgenic factor mGDNF lacking pre- and pro-sequences is not only secreted by cells and stimulates neurite growth in vitro but also demonstrates neuroprotective properties in the neurotoxic model of Parkinson's disease which had been shown several times for the full length GDNF molecule. We have found that mGDNF is more secreted by transfected cells than the pre-pro-GDNF. We confirm by our work that transgenic factor mGDNF stimulates neurite growth and neural differentiation of PC12 cells in vitro. Using the experiments with the injection of transgenic cells to the mice striatum and subsequent system administration of MPTP, we have found that the GDNF isoform retains its neurotrophic properties also in vivo when the factor is secreted into active intracerebral medium which is quite different from the cultural one. Modified transgenic factor secreted by the cells injected into striatum makes indirect retrograde effect on substantia nigra cells. This indicates that mGDNF can be used for treating nerve tissue degeneration observed in a number of nervous system disorders.

\section{Methods}

\section{Genetic constructs and primers}

The mGDNF construct with deleted pre- and proregions and with an EGFP tag was generated by introducing a HindIII site, a Kozak sequence, and an extra start codon upstream of the " $m$ " part as well as by removing the stop codon and introducing a BamHI site in the $3^{\prime}$ region of mGDNF using PCR. The following primers were employed: $G d n f^{\text {HindIII }}(\mathrm{F})$ 
5' -AAGCTTCCACCATGTCACCAGATAAACAA- ${ }^{\prime}$ and $G d n f^{B a m H 1}(\mathrm{R}) 5^{\prime}$-GGATCCCAG ATACATCCACACC TTTTAGCGG-3'. The plasmid pGEM-T Easy (Promega) containing the full-length human GDNF cDNA [25] was used as the template. PCR was performed using the Tersus polymerase (Evrogene) and the following program: $94{ }^{\circ} \mathrm{C}$ for $1.5 \mathrm{~min} ; 25$ cycles of $94{ }^{\circ} \mathrm{C}$ for $15 \mathrm{~s}, 57^{\circ} \mathrm{C}$ for $20 \mathrm{~s}$, and $72{ }^{\circ} \mathrm{C}$ for $15 \mathrm{~s}$; and final $72{ }^{\circ} \mathrm{C}$ for $10 \mathrm{~min}$. The resulting $354 \mathrm{bp}$ (118 amino acids) fragment was isolated from agarose gel using a Qiaquick Gel Extraction Kit (Qiagen) and cloned into pGEM-T Easy (Promega). The HindIII/BamHI fragment of the resulting construct $\mathrm{pGEM} / \mathrm{mGdnf}$ was cloned into the corresponding sites of pEGFP-N1 (Clontech). For the control we used construct with pre-pro-GDNF, which were prepared using the primers T3 (F) 5'-ATTAACCCTCACTAAAGGGA-3' и Gdnf BamH1 5'-TGGATCCCAGA TACACCACACC TTTTAGCGG-3'. This construct was obtained according to the protocol described elsewhere [1].

\section{Transgenic cell cultures}

Human Embryonic Kidney 293 (HEK293) cell line was obtained from the Russian Cell Culture Collection (Institute of Cytology of the Russian Academy of Sciences, St. Petersburg, Russia). HEK293 cells were cultured in complete DMEM (PanEko) supplemented with $10 \%$ fetal calf serum (Perbio HyClone), $2 \mathrm{mM}$ L-glutamine (PanEko), and $10 \mu \mathrm{g} / \mathrm{ml}$ gentamicin (PanEko) at $37{ }^{\circ} \mathrm{C}$ with $5 \%$ $\mathrm{CO}_{2}$ in $25 \mathrm{~cm}^{2}$ Costar flasks. At $70-80 \%$ confluence, the cells were transfected with the generated constructs using ExGen 500 (Fermentas). The transfected clones were selected with $0.4 \mathrm{mg} / \mathrm{ml}$ geneticin (G418, Sigma) for 10 days, after which G418-resistant clones were analyzed by PCR for the inserted gene sequences. The transgene expression was verified by RT-PCR with the corresponding primers.

\section{RT-PCR}

Total RNA was isolated using Tri reagent (Sigma), treated with DNAseI (Thermo Scientific) (1 U per $1 \mu \mathrm{g}$ RNA), and used for reverse transcription with M-MuLV Reverse Transcriptase and oligo (dT) primer. The efficiency of reverse transcription was evaluated by PCR with the primers for GAPDH (F, 5'-GGCCATGAGGTCCACC ACCCTGTTGCTGTA-3'; R, 5'-CCCCTGGCCAAGG TCATCCATGACAACTT-3') and for neomycin (F, 5'-ATGATTGAACAAGATGGATT-3'; R, 5'-TCAGAAG AACTCGTCAAGAA-3'. RNA not subjected to reverse transcription was used as a negative control. The efficiency of transgene expression was evaluated by PCR with the following primers: Gdnf $f^{\text {HindIIII }}$ (F) 5'-AAGCTTCCACCATGTCACCAGATAAACAA- $3^{\prime}$ and $g f p$ (R) $5^{\prime}$-AATAAAGCTTGCATGGCGGTAATACG- ${ }^{\prime}$. The
PCR amplification program consisted of $94{ }^{\circ} \mathrm{C}$ for $2 \mathrm{~min}$; 30 cycles of $93{ }^{\circ} \mathrm{C}$ for $10 \mathrm{~s}, 58{ }^{\circ} \mathrm{C}$ for $20 \mathrm{~s}$, and $72{ }^{\circ} \mathrm{C}$ for $30 \mathrm{~s}$; and final $72^{\circ} \mathrm{C}$ for $5 \mathrm{~min}$.

\section{ELISA}

The 24-h culture media of transgenic HEK293/mGDNF/ GFP, transgenic HEK293/pre-pro-GDNF/GFP, and HEK293 (control) were used in the assay. GDNF was quantified using the GDNF Emax ImmunoAssay System (Promega) and a microplate reader Synergy 4 (Tecan) according to the manufacturer's protocol.

\section{Analysis of mGDNF effect on PC12 cells}

PC12 cells are a clonal cell line derived from a pheochromocytoma of the rat adrenal medulla. They are used as a model for the study of neuronal differentiation [26]. PC12 (ATCC CRL1721) cells were tested for neuronal sprouting after the exposure to conditioned medium containing GDNF with deleted pre- and pro-regions. Transgenic HEK293 cells were plated on $25 \mathrm{~cm}^{2}$ flasks and, after reaching confluence of about $60 \%$, the complete medium was replaced with serum-free DMEM. After $72 \mathrm{~h}$ of culture at $37^{\circ} \mathrm{C}$, the conditioned medium was harvested and filtered through a $0.22 \mathrm{~nm}$ filter.

PC12 cells were plated at $3 \times 10^{4}$ cells/well on four-well plates coated with rat tail type I collagen in RPMI1640 containing $10 \%$ horse serum, $2 \mathrm{mM} \mathrm{L}$-glutamic acid, and $100 \mu \mathrm{g} / \mathrm{ml}$ streptomycin. After $4 \mathrm{~h}$ of culture, the medium was replaced with that conditioned by transgenic HEK/ mGDNF/GFP cells. The medium conditioned by untransfected HEK293 cells for $72 \mathrm{~h}$ was used as control. The concentration of chimeric GDNF proteins was evaluated in the media conditioned by transgenic HEK293 cells for further analysis. This concentration was confirmed by ELISA. Based on the obtained data, the concentration of $\sim 1.25 \mathrm{ng} / \mathrm{ml}$ was used to analyze the chimeric protein activity in vitro. The following controls were used: (1) medium conditioned by HEK293 cells transgenic for GFP; (2) medium supplemented with $1.25 \mathrm{ng} / \mathrm{ml}$ recombinant GDNF (SantaCruz); (3) unconditioned complete culture medium. After a 3-day culture in conditioned or control medium, PC12 cells were fixed in $4 \%$ formaldehyde and analyzed by phase contrast microscopy under an inverted microscope Olympus IX81. Then these cells were stained using the primary polyclonal antibodies against $\beta$-3-tubulin (Abcam) and secondary Cy2-conjugated donkey anti-rabbit antibodies. After washing in PBS, cells were mounted in glycerol and analyzed under an inverted fluorescent microscope Olympus IX81. The proportion of cells with axons equal to or longer than the small diameter of the cell was counted on phase contrast and fluorescent images using the ImageTool software (UTHSCSA) [27]. Five counts including 100-120 cells 
were carried out for each studied construct. The obtained data were analyzed using the SPSS software (IBM, USA).

\section{Cell transplantation and electrode implantation for electroencephalographic analysis of the sleep-waking cycle}

The neuroprotective effect of transgenic mGDNF encoded by the GDNF gene with deleted pre- and proregions on the viability of dopaminergic neurons in the substantia nigra pars compacta was studied in the early Parkinson's disease model. Transgenic cells were injected into the striatum (the caudate nucleus/putamen region) of mice 3 days prior to subcutaneous administration of $40 \mathrm{mg} / \mathrm{kg}$ of the proneurotoxin MPTP.

Four groups of animals were studied:

1. Animals transplanted with transgenic HEK293/ mGDNF/GFP cells 3 days prior to MPTP injection $(\mathrm{N}=10)$.

2. Animals transplanted with HEK293/GFP cells without the GDNF gene 3 days prior to MPTP injection $(\mathrm{N}=10)$.

3. Animals transplanted with transgenic HEK293/ mGDNF/GFP cells with no subsequent MPTP injection $(\mathrm{N}=5)$.

4. Animals injected with MPTP without preliminary cell transplantation $(\mathrm{N}=11)$.

All in vivo experiments were approved by the Ethics Committee of Moscow State University. Animals anesthetized by chloral hydrate were placed in a stereotaxic frame. Transgenic HEK293/mGDNF/GFP cells were injected into the striatum of $\mathrm{C} 57 \mathrm{BL} / 6 \mathrm{j}$ mice at the age of 2.5-3 months weighing 25-30 g (groups 1 and 3). A suspension containing about 150,000 cells in $1 \mu \mathrm{l}$ of Hanks solution was bilaterally injected into the brain. The injection was performed slowly (over a period of $3 \mathrm{~min}$ ) with a microsyringe at coordinates AP $0 \mathrm{~mm}$ and ML $2.5 \mathrm{~mm}$ (the caudate nucleus/putamen region). The needle was inserted to a depth of $2.5 \mathrm{~mm}$ and withdrawn in steps to a depth of $1.5 \mathrm{~mm}$. HEK293/GFP cells were injected similarly into animals of group 3. Next, four epidural electrodes were permanently implanted for electroencephalographic (EEG) monitoring in the frontal and parietal neocortex. The reference electrode was placed on the nasal bone. Animals of group 4 were not transplanted with cells, while the electrodes were implanted as described above. After implantation, animals were placed into small individual soundproof boxes equipped with highly sensitive module video cameras attached to a video recorder, which was consequently connected to a PC via USB port. Animals were kept under a 12/12 light/ dark cycle (09-21 h, bright white light; 21-09, dim red light), temperature $22-24{ }^{\circ} \mathrm{C}$, and free access to food and water.

Each animal was attached via a flexible cable to a miniature digital two-channel biopotential amplifier supplied with a three-axis accelerometer (for mechanographic monitoring) attached via a flexible spring to an independent power supply, which was consequently attached to rotatable hook in the box ceiling. This construction allowed three-axis motions of the amplifier plate $(30 \times 28 \times 7 \mathrm{~mm}$ in size and $8 \mathrm{~g}$ in weight $)$ in response even to faint movements of the animal. The digitization frequencies of the EEG and accelerometer signals were 250 and $50 \mathrm{~Hz}$, respectively. The signal from wireless amplifiers was transmitted via Bluetooth channel to the recording computer and visualized using the modified open-source software EDF browser [28]. The EEG and accelerometer bandwidths were set equal to 1-20 and 1-12 Hz, respectively. The animal behavior and motor activity were also monitored by video tracking. Animals of group 4 had a 7 -day recovery period after implantation. After this period, the EEG (background) and mechanographic monitoring was continuously performed for $24 \mathrm{~h}$. Such monitoring was repeated 7 and 14 days after MPTP administration. Experimental conditions allowed no long recovery period and, thus, no background EEG recording for animals of the first three groups. Accordingly, only the dynamics of the sleep-wakefulness cycle was evaluated 7 and 14 days after MPTP administration in comparison to the baseline records in group 4 animals.

\section{MPTP administration and analysis of its effects}

Three days after cell transplantation and electrode implantation, animals of groups 1,2 , and 4 were subcutaneously injected $40 \mathrm{mg} / \mathrm{kg}$ of the dopaminergic proneurotoxin MPTP (Sigma, St. Louis, MO, USA). One and two weeks later, EEG and mechanographic (by accelerometer) records were made. The polysomnograms (EEG + mechanogram) obtained for all animals were visually evaluated for 20-s epochs. Wake as well as NREM and REM sleep stages were identified using the standard criteria: wake, desynchronized cortical EEG, 5-7 Hz hippocampal theta-rhythm in the parietal (hippocampal projection) EEG, and high accelerometer signal; NREM sleep, high delta and sigma EEG activity and low accelerometer signal; REM sleep, very high and regular 6-8 Hz thetarhythm in the parietal-hippocampal EEG and zero accelerometer signal [29]. The data obtained were analyzed by nonparametric statistical methods using the GraphPad/ Prism-4.02 software (Friedman and Kruskal-Wallis analysis of variance, post hoc Dunn's test, and Wilcoxon and Mann-Whitney tests).

After the experiment, the motor coordination of experimental animals was tested on a Rotarod (TSE Systems, 
Bad Homburg, Germany). Animals were exposed to $6 \mathrm{rpm}$ for $10 \mathrm{~min}$, after which the rotational speed was increased in steps of $1 \mathrm{rpm}$ every $30 \mathrm{~s}$ until the animal fell onto the tray with wood shavings. The time of falling and velocity were recorded.

Fifteen days since MPTP administration (18 days after transgenic cells injection) the animals were anesthetized again and perfused through the heart with PBS and then with $4 \%$ formaldehyde in PBS. The brain was isolated, fixed again in formaldehyde for $12 \mathrm{~h}$ at $4{ }^{\circ} \mathrm{C}$, and soaked in $30 \%$ sucrose in PBS for $24 \mathrm{~h}$. The cryotome coronal sections of the brain $(40 \mu \mathrm{m})$ were mounted in PBS. Four series of sections were prepared for each brain. The sections in antifreeze solution were stored at $-20{ }^{\circ} \mathrm{C}$ until staining. Every fourth section containing the substantia nigra was immunohistochemically stained for tyrosine hydroxylase $(\mathrm{TH})$ using monoclonal antibodies (Sigma) diluted 1:200 in PBS with $2 \%$ normal horse serum, $0.5 \%$ Triton X-100, and $0.01 \%$ sodium azide (Sigma). Free-floating sections were incubated in primary antibodies at $4{ }^{\circ} \mathrm{C}$ for $48 \mathrm{~h}$. After incubation in biotinylated horse anti-mouse antibodies diluted 1:100 (Vector Labs, Burlingame, CA, USA) and then in ABC diluted 1:200 (Vector Labs), the standard staining for peroxidase was performed using PBS with $0.03 \%$ diaminobenzidine (Sigma) and $0.01 \%$ hydrogen peroxide. The stained sections were mounted on slides in $50 \%$ glycerol and covered with slips. TH-immunopositive $(\mathrm{TH}+)$ cells were quantified on an Olympus IX81 microscope with a computer-controlled motorized stage (Märzhäuser, Wetzlar, Germany) and an Olympus DP72 digital camera (Olympus, Münster, Germany). Cells were counted using the Cell* software (Olympus Soft Imaging Solution, Münster, Germany). After obtaining an overview of the compact part of the substantia nigra (SNC) and the ventral tegmental area (VTA) at a low magnification $(10 \times$ objective), $\mathrm{TH}+$ cells were counted using the optical fractionator method [30] at a higher magnification (40× objective). The $50 \times 50 \mu \mathrm{m}$ counting frame was shifted in $200 \mu \mathrm{m}$ steps in both X- and Y-directions within the ventral part of the midbrain. At each position of the counting frame, the focal plane was shifted in the $\mathrm{Z}$ direction by $30 \mu \mathrm{m}$. An uninformed operator counted unstained nuclei of $\mathrm{TH}+$ cells in counting frames.

\section{Western blot hybridization}

To know how long the transgenic HEK293/mGDNF/GFP cells can survive in striatum and produce fusion protein mGDNF/GFP we used Western Blot analysis. Two, three, five and eighteen days since administration of transgenic cells we cut out fragments of mouse striatum in a volume of 3-4 $\mathrm{mm}^{3}$ which include the site of injection, then powdered them in a liquid nitrogen and lysed in the following buffer (100 $\mu \mathrm{l}$ per 106 cells): $60 \mathrm{mM}$ Tris- $\mathrm{HCl}(\mathrm{pH} 6.8)$, $25 \%(\mathrm{v} / \mathrm{v})$ glycerol, $2 \% \mathrm{SDS}, 5 \%$ (v/v) 2-mercaptoethanol, and $0.01 \%(\mathrm{w} / \mathrm{v})$ bromophenol blue. Protein concentration was determined by Bradford assay and $40 \mu \mathrm{g}$ protein samples were loaded onto a $10 \%$ gel and analyzed by SDS-PAGE. Proteins were transferred to a Hybond ECL membrane (Amersham, Buckinghamshire, UK) using a Mini trans-Blot cell (Bio-Rad \#170-3930) according to the manufacturer's instructions in the buffer containing $25 \mathrm{mM}$ Tris, $192 \mathrm{mM}$ glycine, and $20 \%$ (v/v) methanol, $\mathrm{pH} 8.3$ at $100 \mathrm{~V}$ for $1 \mathrm{~h}$. The membrane was stained with Ponceau Red and thoroughly rinsed with TBS-T buffer. Then the membrane was incubated on a shaker in $5 \%$ defatted milk powder in TBS-T at room temperature for $30 \mathrm{~min}$ and washed three times with TBS-T for $5 \mathrm{~min}$. GDNF was detected using monoclonal antibodies against GDNF (D20, Santa Cruz Biotechnology, Dallas, USA). The membrane was incubated with the primary antibodies at $4{ }^{\circ} \mathrm{C}$ overnight and washed with TBS-T. Incubation with the secondary peroxidase-conjugated antibodies (1:3000) was carried out at room temperature for $1 \mathrm{~h}$, and the membrane was washed with TBS-T. GDNF detection was performed using an ECL Advance Western Blotting Detection Kit (Amersham) according to the manufacturers' instructions. In each group there were 3 mice with the same surviving time since the cell administration. The intensity of the bands were measured using ImageJ [31].

\section{Statistical analysis}

Data are presented as mean \pm SEM. The statistical analysis was performed using the SPSS software. The values were compared by one-way ANOVA followed by Tukey's multiple comparisons test. Statistical significance was accepted at $\mathrm{p}<0.05$.

\section{Results}

\section{Quantitative analysis of GDNF released from transgenic cells}

The transgenic culture of human embryonic kidney cells HEK293 producing mGDNF/GFP was obtained using the protocol described elsewhere [1]. The release of the fusion mGDNF/GFP protein from transgenic HEK293 cells was evaluated by ELISA. Each experiment was done in triplicates. The medium conditioned by untransfected HEK293 cells was used as control. HEK293 cells were cultured in DMEM containing $10 \%$ fetal serum, $2 \mathrm{mM}$ L-glutamine at $37{ }^{\circ} \mathrm{C}$ in a $\mathrm{CO}_{2}$ incubator. GDNF was quantified using the GDNF Emax ImmunoAssay System. mGDNF/GFP was shown to be released to the culture medium of the transgenic cells. The level of released mGDNF/GFP was much higher than that of the fulllength pre-pro-GDNF/GFP (Fig. 1). Likewise, mGDNF level in the conditioned medium was also much higher 


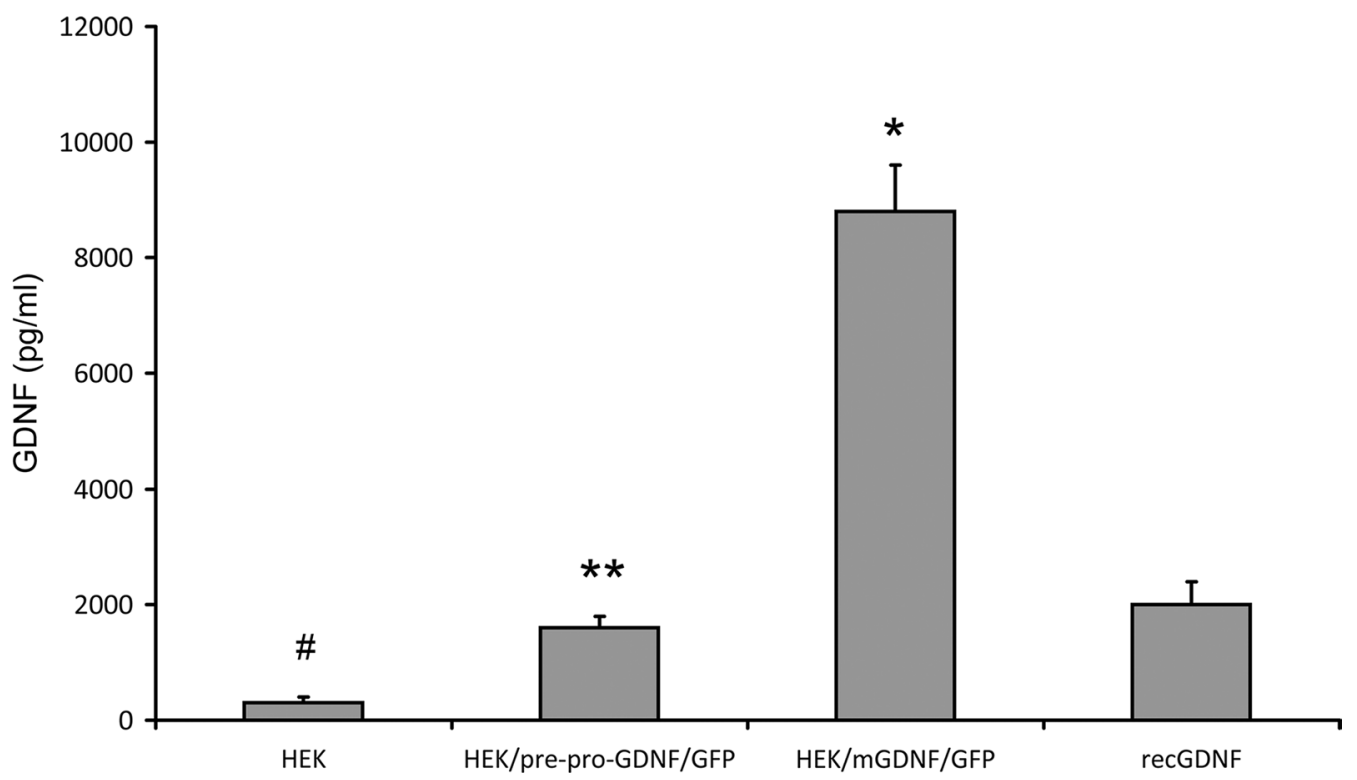

Fig. 1 Quantitative analysis of GDNF in medium conditioned by transgenic and control untransfected HEK293 using ELISA. (HEK) medium conditioned by untransfected HEK293 cells; (pre-pro-GDNF/GFP) medium conditioned by HEK293 cells transfected with pre-pro-GDNF/GFP; (mGDNF) medium conditioned by HEK293 cells transfected with mGDNF/GFP; (recGDNF) medium fortified with recombinant GDNF (SantaCruz) diluted to a concentration of $2 \mathrm{ng} / \mathrm{ml}$. Data are presented in $\mathrm{pg} / \mathrm{ml}$ as mean \pm SEM $(n=3)$. Differences between values are significant at ${ }^{*} p<0.01$ as compared with all other values. ${ }^{* *} p<0.05$ as compared with HEK293. ${ }^{*} p<0.05$ as compared with recGDNF (one-way ANOVA)

compared to pre-pro-GDNF/GFP. The observed experimental differences were significant at $\mathrm{p}<0.05$ (one-way ANOVA).

\section{The influence of conditioned media containing mGDNF/ GFP on neurite outgrowth in PC12 cells}

The efficiency of conditioned media containing mGDNF/ GFP was analyzed using PC12 cells. After 3-day culture in conditioned medium with GDNF lacking the preand pro-regions as well as with recombinant GDNF, the proportion of cells with axons (exceeding the neuronal body size) was significantly higher than that in control cultures at $\mathrm{p}<0.05$ (Fig. 2). One-way ANOVA indicated significant differences between the control cells cultured in medium conditioned by untransformed HEK293 cells and those cultured in the normal unconditioned medium. The proportion of cells with axons cultured in medium conditioned by transgenic HEK293/mGDNF/GFP cells was substantially and significantly higher than that in control cells cultured in unconditioned medium. The difference between cells cultured in media conditioned by transgenic HEK293/mGDNF/GFP and HEK293/pre-promGDNF/GFP was also significant. The highest proportion of cells with axons was observed in cells cultured in medium conditioned by HEK293/mGDNF/GFP.

Figure 3 demonstrates immunohistochemical staining of PC12 cells exposed to media conditioned by HEK293 cells transfected with pre-pro-GDNF/GFP and mGDNF/ GFP, by untransfected HEK293 (HEK), and in unconditioned medium. Thus, the removal of the pre- and pro-regions did not affect the transport of this GDNF modification from the cell and improved the inductive properties of the factor.

\section{Analysis of protective properties of the GDNF modification in vivo using the mouse MPTP model of Parkinson's disease}

Histological studies of changes in the substantia nigra and ventral tegmental area

Analysis of sections prepared from animals sacrificed 17 days after the injection of $40 \mathrm{mg} / \mathrm{kg}$ of MPTP demonstrated significant changes in the number of dopaminergic neurons in the substantia nigra pars compacta between the experimental and control animals (Figs. 4, 5). Control animals injected with MPTP alone demonstrated a significant decrease in the number of $\mathrm{TH}+$ neurons in the ventral midbrain. In SNC, the number of $\mathrm{TH}+$ neurons decreased by $78 \%$; in VTA, by $54 \%$ relative to control; while the overall number of $\mathrm{TH}+$ neurons decreased by $67 \%$ (Fig. 5). The number of $\mathrm{TH}+$ neurons in these midbrain structures in animals transplanted with cells expressing the GDNF gene with deleted pre- and prosequences (HEK293/mGDNF/GFP + MPTP) was significantly higher than that in animals of two control groups 


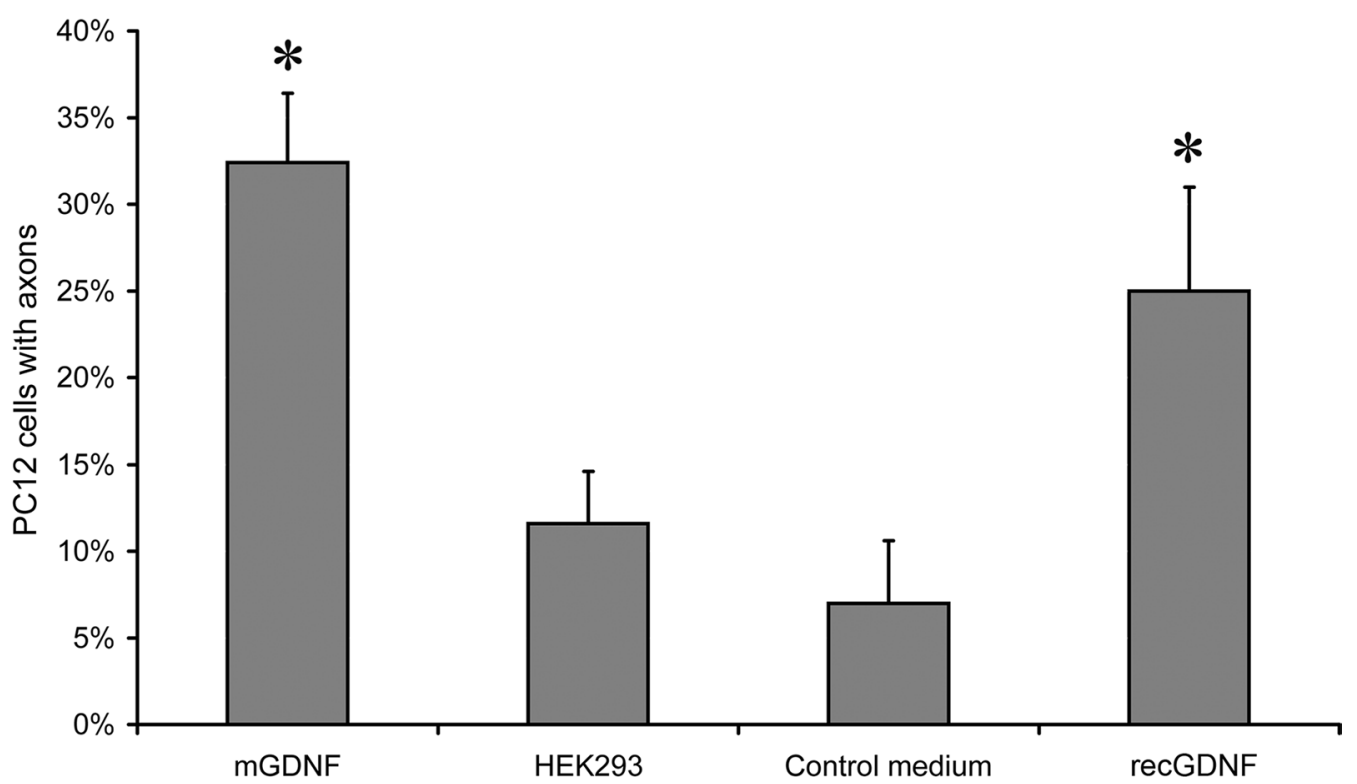

Fig. 2 Percentage of PC12 cells with axons after 3-day culture in media conditioned by transgenic cells or in control media. (recGDNF) medium fortified with $1.25 \mathrm{ng} / \mathrm{ml}$ pre-pro-GDNF (SantaCruz); (HEK293/mGDNF) medium conditioned by HEK293/mGDNF/GFP with mGDNF/GFP adjusted to $1.25 \mathrm{ng} / \mathrm{ml}$; (HEK293) medium conditioned by untransformed HEK293 cells; (control medium) unconditioned medium—serum-free DMEM. ${ }^{*} \mathrm{p}<0.05$ as compared with HEK293 and control medium

administered MPTP alone or after transplantation with cells without transgenic GDNF (HEK293/GFP + MPTP).

The caudate-putamen locus where HEK293/mGDNF/ GFP and HEK293/GFP cells were injected was examined on the brain sections crossing the striatum using fluorescence microscopy. In all cases, the transplantation loci were in the middle part of the caudate-putamen (Fig. 6a). At the same time, nearly no GFP-positive cells were found in the stratum of experimental animals, which can be due to a long period of time passed after transplantation. Control animals transplanted with HEK293/ mGDNF/GFP or HEK293/GFP cells were sacrificed 3 days after transplantation. These controls demonstrated GFP-positive transgenic cells in the transplantation site (Fig. 6b). Immunohistochemical analysis using antibodies against GDNF demonstrated that HEK293/mGDNF/GFP cells expressed transgenic GDNF 3 days after transplantation into the stratum (Fig. 6c).

\section{Analysis of motor coordination}

In our experiments, mice of all groups could retain on the rotarod at $6 \mathrm{rpm}$ for $10 \mathrm{~min}$. As the speed increased, experimental groups demonstrated substantial differences in the threshold speed of the animal falling down. Mice of group 1 transplanted with cells expressing modified GDNF without the pre- and pro-regions prior to MPTP administration demonstrated the best results remaining on the rotarod at $21 \mathrm{rpm}$, while mice of groups
2 and 4 transplanted with cells without the GDNF gene or not transplanted fell down at the speed of 12-14 rpm (Fig. 7). The results for group 1 significantly differed from those for groups 4 and $2(\mathrm{p}<0.05)$.

\section{EEG and behavioral analysis}

EEG was recorded 7 and 14 days after MPTP administration. The injection of this proneurotoxin into control mice (group 4) gradually increased the wake time and decreased the NREM sleep time during the dark period. These changes observed on day 7 became significant by the day 14 (Figs. 4, 5a). The REM sleep time did not significantly change and demonstrated only a trend to decrease. No notable changes were observed during the light period (Fig. 8).

Transplantation of transgenic HEK293/mGDNF/ GFP cells into animals of group 1 prior to MPTP injection dampened these effects (Fig. 9b). If cells without the GDNF gene were transplanted (group 2), no dampening was observed, and the pattern of changes was similar to that of group 4 (Fig. 9c). Animals of group 3 demonstrated no significant differences from the baseline of group 4 (Fig. 9d).

\section{Discussion}

The capacity of GDNF to induce axonal growth in neuronal precursors in vivo suggests that it can be used to inhibit neurodegenerative process and prevent neuronal 

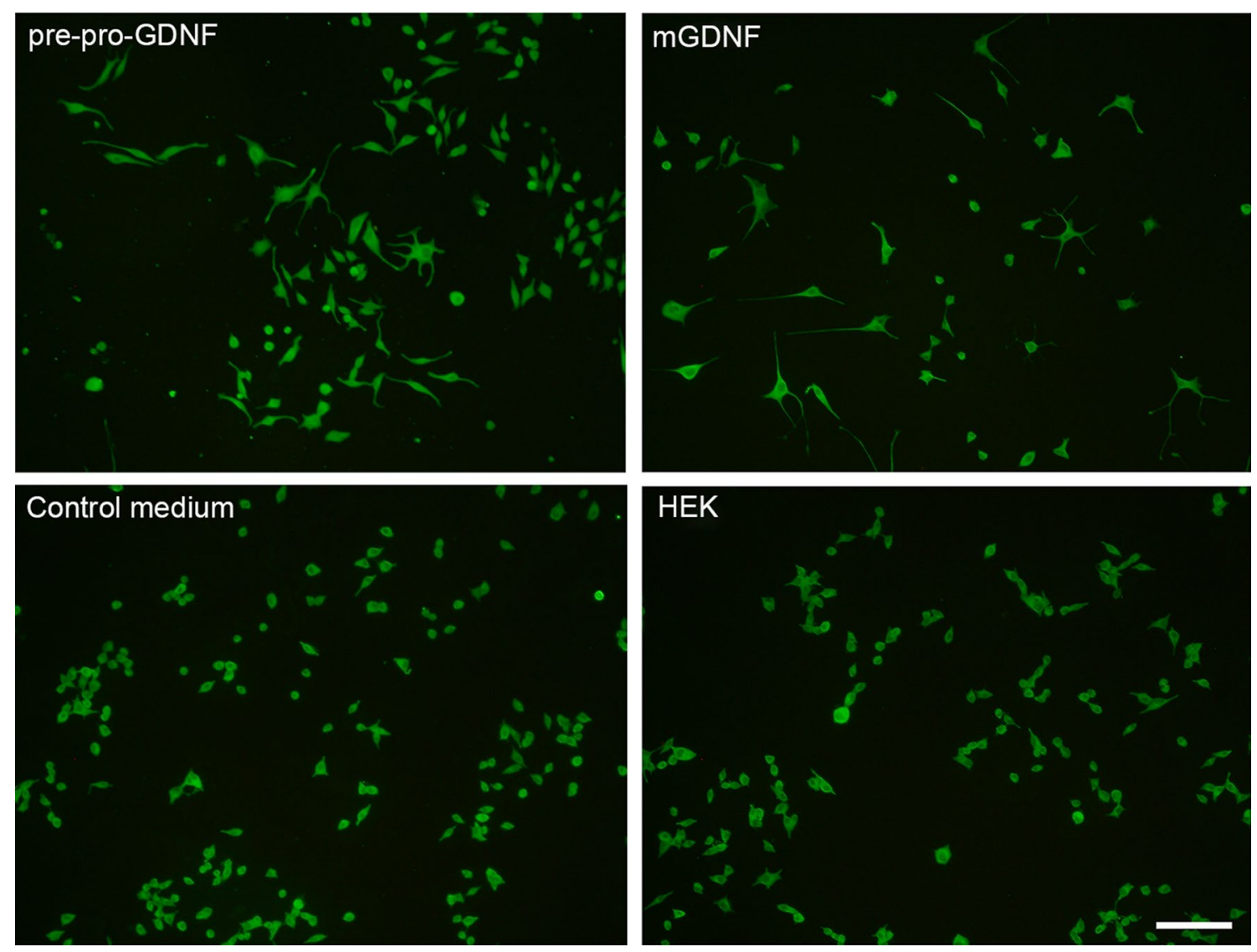

Fig. 3 PC12 cells immunocytochemically stained for $\beta$-tubulin after culture in media conditioned by transgenic cells or in control media. (pre-proGDNF) media conditioned by HEK293 cells transfected with pre-pro-GDNF/GFP; (mGDNF) media conditioned by HEK293 cells transfected with mGDNF/GFP and mGDNF/GFP; (control medium) unconditioned medium — serum-free DMEM; (HEK) media conditioned by untransfected HEK293. Cells cultured in media conditioned by transfected cultures demonstrate a significantly higher proportion of cells with axons. Scale 100 um (right lower corner)

death following ischemic stroke or during neurodegenerative diseases $[2-5,7,8,26]$. However, clinical trials in Parkinson's disease patients after intracerebroventricular administration of recombinant GDNF demonstrated minor or no clinical improvements. A significant effect was initially observed after a direct infusion of recombinant GDNF into the striatum [32]; however, it has not been confirmed by a phase II double-blind trial conducted by Amagen so further clinical trials were discontinued. Nevertheless, well-documented protective properties of GDNF tempt both scientific and pharma specialists to find a way to using it as a neurodegenerative drug. For instance, MedGenesis Therapeutix and Pfizer made an agreement for joint development of methods for GDNF application and the convection enhanced delivery method in Parkinson's disease.

One of possible approaches is a change of recombinant GDNF molecule through a modification of the vector bearing its gene. The presence of 2 splice variants of the matrix RNA of GDNF gene can indicate their different functions [33-36]. In our pervious study [1] we have studied the cell secretion and functional activity of various GDNF isoforms. For this purpose, we transfected HEK293 cells using plasmid constructions involving 4 different GDNF gene isoforms: a modification with pre- and pro-sequences (pre-pro-Gdnf); modification with pre- sequence only (pre-Gdnf); modification with pro- sequence only (pro-Gdnf); modification without both pre- and pro-sequences (mGdnf). In vitro experiments demonstrated that deleting pro-sequences as well as simultaneous deleting both pre- and pro-sequences of GDNF do not prevent the factor's secretion by the cell and do not decrease its neurotrophic activity.

Here, we used ELISA to demonstrate a substantial and significant improvement in the release of transgenic GDNF without pre- and pro-regions from transfected cells compared to that with intact pre- and pro-regions. In vitro experiments on $\mathrm{PC} 12$ cells demonstrated that 


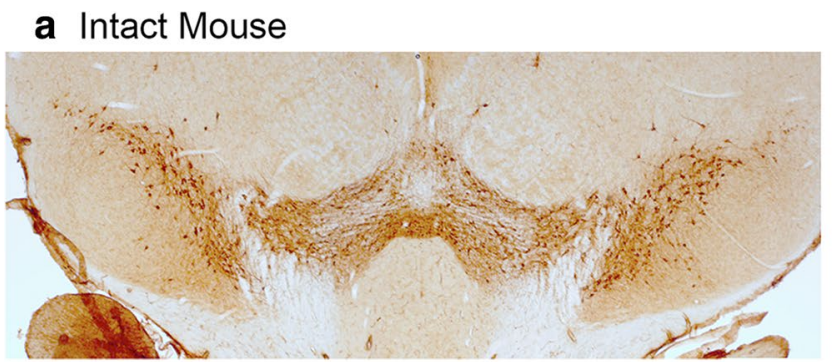

\section{c $\mathrm{HEK} / \mathrm{mGDNF}+\mathrm{MPTP}$}

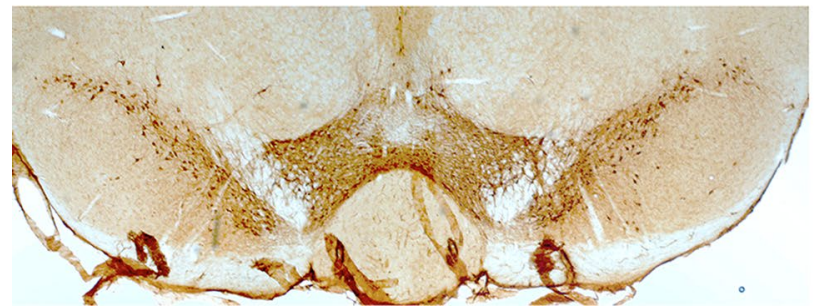

b MPTP

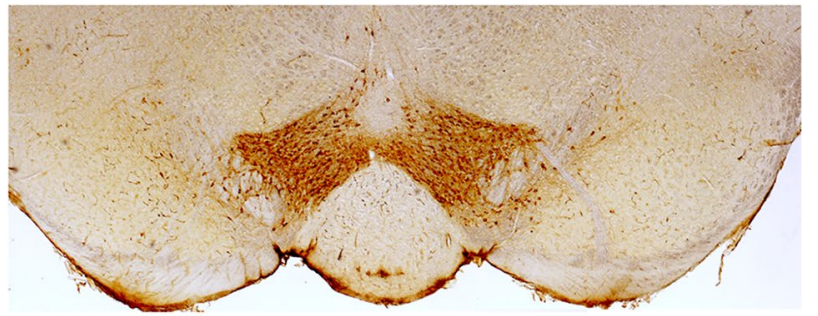

d HEK + MPTP

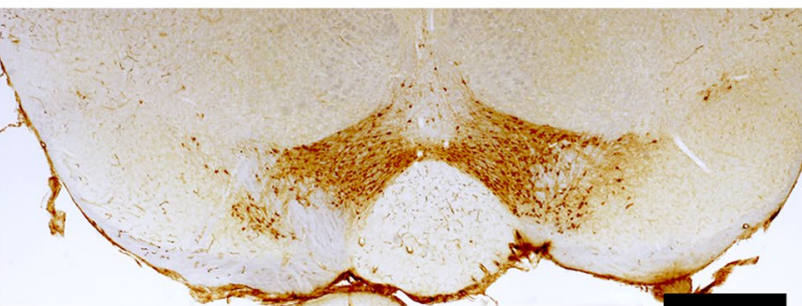

Fig. 4 Representative micrographs of coronal sections of the ventral midbrain in an intact and MPTP treated animals. a Intact mouse, $\mathbf{b}$ a mouse after MPTP injection; c a mouse transplanted with HEK293/mGDNF/GFP cells 3 days prior to MPTP injection; d a mouse transplanted with HEK293/ GFP cells 3 days prior to MPTP injection. Scale $500 \mu \mathrm{m}$ (right lower corner)

the differentiation activity of transgenic GDNF with deleted pre- and pro-regions is as high as that of recombinant GDNF with intact pre- and pro-regions. So GDNF can be secreted from the cell even at the absence of the sequences which are necessary for regulation of the process of its secretion. Uncontrolled intensive secretion of GDNF may be useful for the construction of gene-cellular therapeutic drugs if the high concentration of the gene product must be achieved at the site of transgenic cell transplantation. The data obtained suggest that the genetic constructs containing GDNF with deleted preand pro-regions can become more efficient in gene therapy compared to full-length GDNF variants.

Important advantage of gene-deleted constructions without pre- and pro-sequences is inability to secreting GDNF pro-forms from the transgenic cells. Mature forms of many neurotrophic factors (NGF, BDNF, NT3) realize their neuroprotective and differential activity via tyrosine kinase receptors $(\operatorname{Trk} A, \operatorname{Trk} B$ and $\operatorname{Trk} C)$. At the same time their pro-forms which may be also synthesized and secreted from neurons and glia induce apoptosis via p75NTR-sortilin signaling cascades [37-41]. Regarding the GDNF, it is known that in a case of overexpression after plasmid transfection unprocessed proGDNF can be also secreted from the cell $[17,42]$. proGDNF activity in the brain is insufficiently studied, however it is known that its expression increased in the ventral part of midbrain in MPTP mouse model of Parkinson's disease. In rat LPS model, proGDNF is expressed in nigral neurons and glia [43]. One may propose that proGDNF may be involved into pathogenesis of Parkinson's disease and does not counteract pathological disorders. In this case the lack of the pro-sequence in a transgene will be in favor of the therapeutic effect of transfected cells.

The main purpose of the study is to check up neuroprotective properties of mGDNF construction in vivo when the mature protein is secreted not to the cultural but the active intercellular medium. We used the mouse MPTP model of Parkinson's disease to evaluate neuroprotective properties of the construct with mGDNF in vivo. MPTP injection considerably decreased the number of $\mathrm{TH}+$ neurons in the ventral midbrain of experimental animals. The transplantation of transgenic cells with the GDNF gene lacking the pre- and pro-regions into the caudate-putamen of mice 3 days prior to MPTP injection substantially neutralized the negative impact of the proneurotoxin. Under these conditions, the MPTP induced a smaller decrease in the number of $\mathrm{TH}+$ neurons in experimental animals compared to those transplanted with no cells or cells expressing no transgenic GDNF. It should be noted, after all, that the transplantation of HEK293 cells containing no transgenic GDNF prior to MPTP administration also has some neuroprotective effect on dopaminergic neurons in the substantia nigra pars compacta and the ventral tegmental area. This is indicated by a significant increase in calculated $\mathrm{TH}+$ neurons as compared to animals not subjected to transplantation. A similar protective effect of untransfected cells was described by Cunningham and $\mathrm{Su}$ [12]. Following the authors, one can putatively attribute this effect 
a Compact Part of the Substantia Nigra

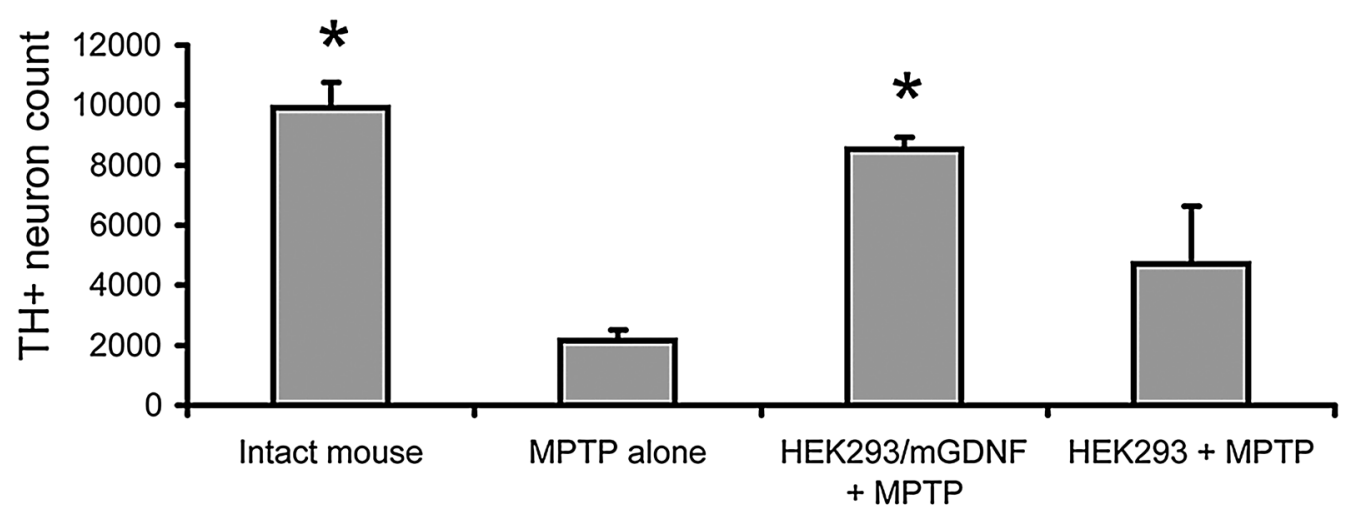

b Ventral Tegmental Area
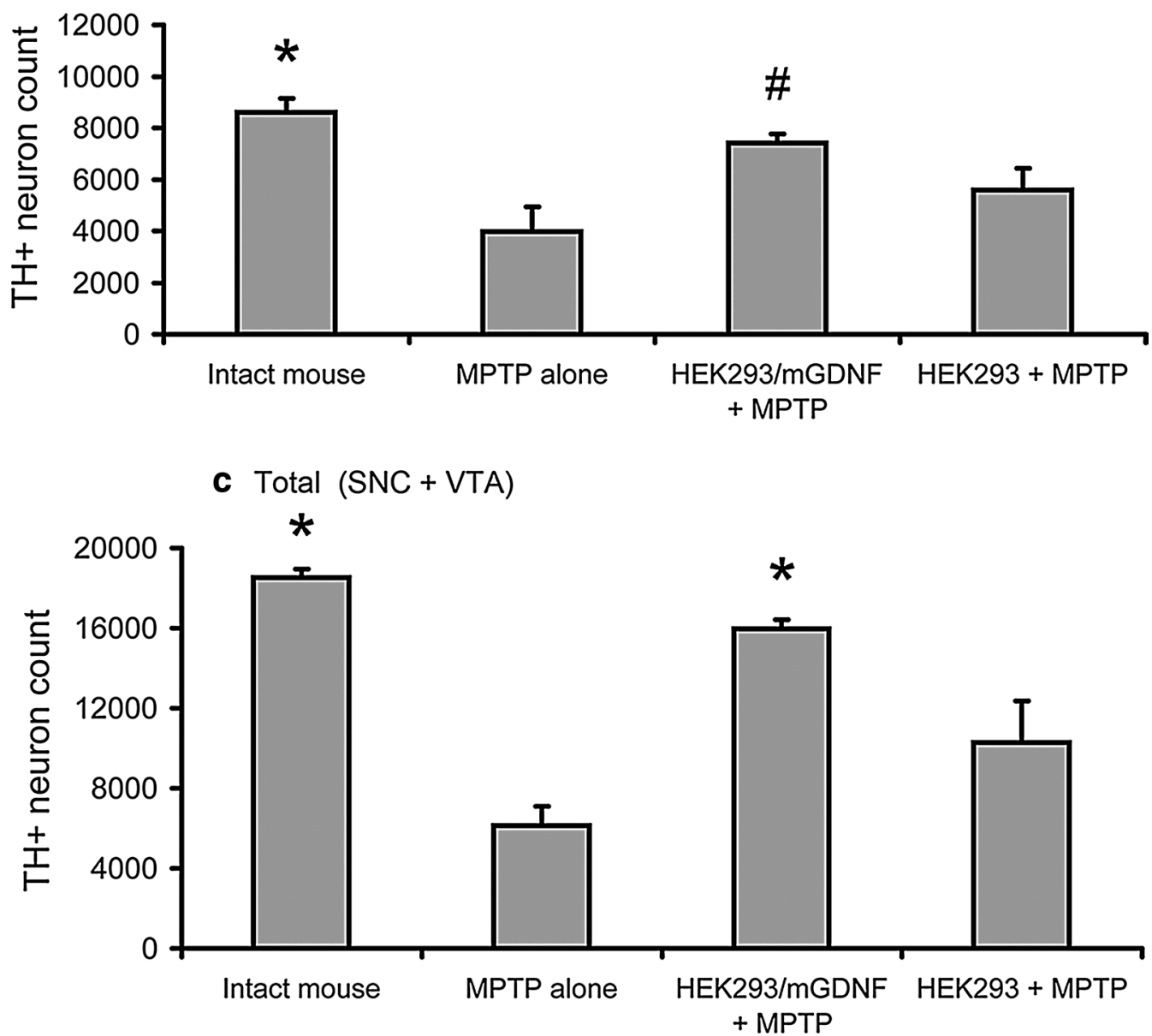

Fig. $5 \mathrm{TH}+$ neuron counts in the ventral midbrain (SNC and VTA) in intact and MPTP treated animals. a TH+ neuron counts in the substantia nigra pars compacta. b TH+ neuron counts in the ventral tegmental area. c Total number of TH+ neuron in ventral midbrain. (MPTP) group 4 animals injected with MPTP only; (HEK293/mGDNF + MPTP) group 1 animals transplanted with HEK293/mGDNF/GFP 3 days prior to MPTP injection; (HEK293 + MPTP) group 2 animals transplanted with HEK293/GFP cells prior to MPTP injection. * $p<0.05$ as compared with MPTP only and HEK293/ GFP. $\#$ $<0.05$ as compared with MPTP only 

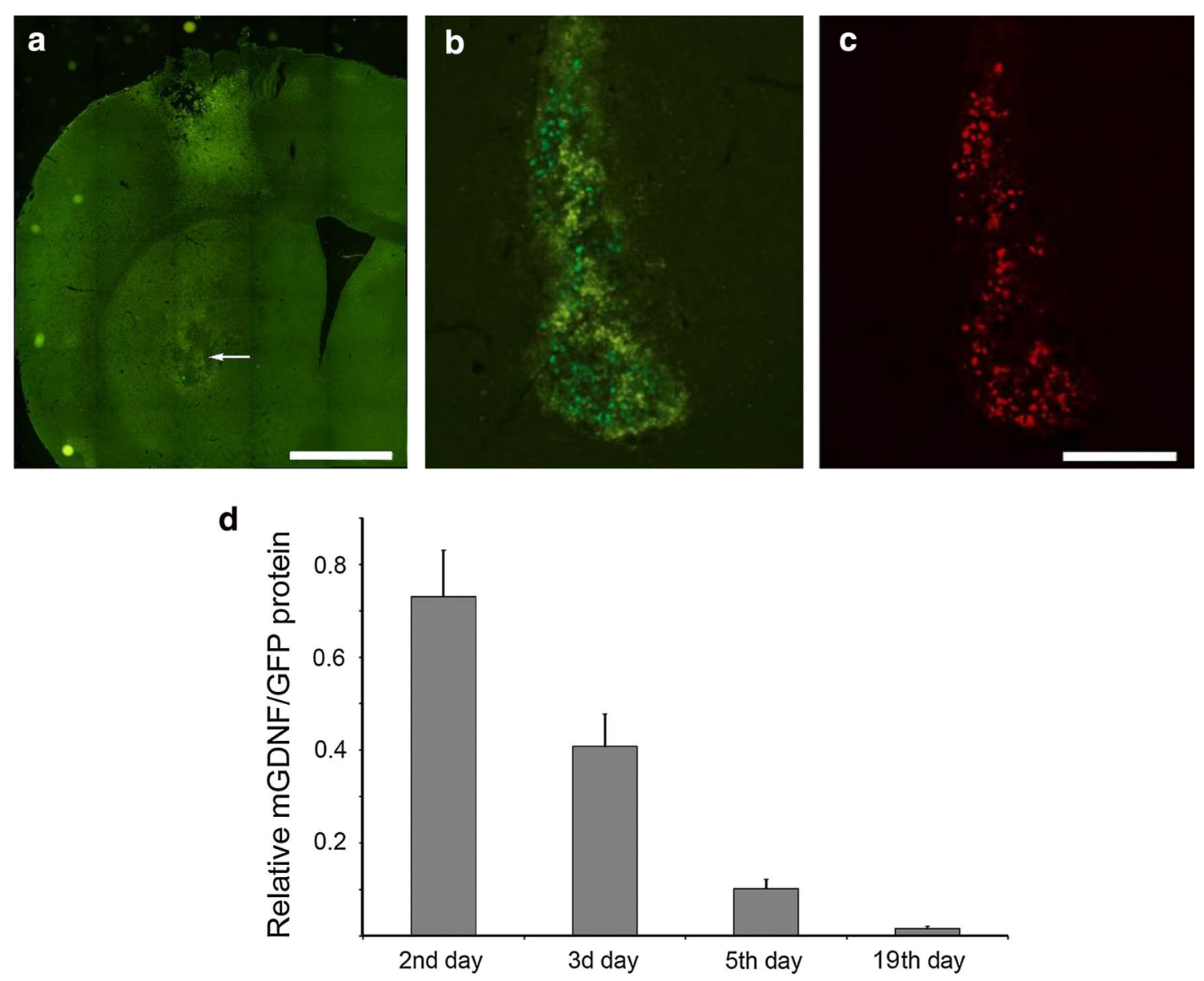

mGDNF 40kDa

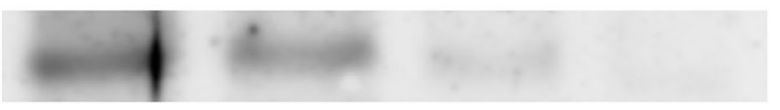

\section{$\beta$-tubulin $50 \mathrm{kDa}$}

Fig. 6 The time-dependent mGDNF level in the striatum after HEK/mGDNF/GFP transplantation. a-c Representative fluorescence micrographs of coronal sections of the striatum in the transplantation site. a GFP-expressing cells were almost missing in the injection site (indicated by the arrow) in the caudate-putamen of animals sacrificed 19 days after transplantation of transgenic cells containing the modified GDNF. One can see two GFPexpressing cells. $\mathbf{b}$ mGDNF/GFP-producing cells 3 days after transplantation into the striatum of mouse brain. $\mathbf{c}$ The same section immunohistochemically stained for GDNF (visualized by Texas red-conjugated secondary antibodies). Scale in a $1 \mathrm{~mm}$, in b, c (shown on c) $200 \mu \mathrm{m}$. d The results of Western blot analysis of mGDNF/GFP expression in striatum 2, 3, 5, 18 days after cell administration

to a weak trophic impact of injected cells or to the effect of factors released by brain cells injured by injection of a large volume of cells.

The test on rotating rod (rotarod) is conventionally used to evaluate functional disturbances in this model [20]. This test demonstrated a smoothing of MPTP effect on the motor abilities of experimental animals after the transplantation of cells transfected with the GDNF gene without the pre- and pro-sequences. A minor attenuation of MPTP effect was also observed after the transplantation of cells without GDNF into the striatum; however, this effect did not significantly differ from control with MPTP injection without cell transplantation.

We also evaluated the effect of cells releasing GDNF without the pre- and pro-regions on the non-motor consequences of MPTP administration described previously [23]. In present experiments as well as the cited publication, mice demonstrated increased motor activity, elongated total wake time, and shortened NREM and REM sleep time during the darkness (period of diurnal activity) 


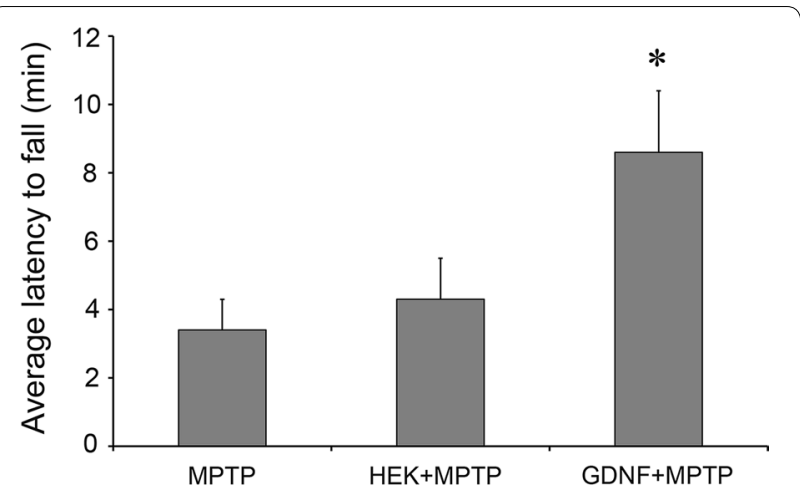

Fig. 7 Rotarod test of mice of groups 1,2, and 4. The results for mice of group 4 injected with MPTP only (MPTP, N =11), group 2 transplanted with HEK293/GFP cells prior to MPTP injection (HEK + MPTP, $N=10$ ), and group 1 transplanted with HEK293/mGDNF/GFP cells prior to MPTP injection ( $m G D N F+M P T P, N=10)$. Ordinate, rotarod speed when animals fell down after a $30 \mathrm{~s}$ exposure normalized to group $4(100 \%)$, mean \pm SEM. *Difference from group 4 significant at $p<0.05$

within two weeks after systemic MPTP administration. These changes are observed in the same circadian period of pineal melatonin production when the corresponding sleep disorders are observed in Parkinson's disease patients [24]. The transplantation of cells with transgenic
GDNF lacking the pre- and pro-regions into the striatum 3 days prior to MPTP administration efficiently antagonized these changes. In contrast to the MPTP control, the sleep-wake ratio during the dark period was the same on days 7 and 14. At the same time, the transplantation of control HEK293/GFP cells into the same striatum region had no effect on the MPTP-induced changes in the sleep-wakefulness cycle (group 2). The transplantation of transgenic mGDNF-expressing cells without subsequent MPTP administration also had no effect on the sleep-wakefulness cycle (group 3). It may be concluded that namely the GDNF protein released by HEK293/ mGDNF/GFP cells is the factor antagonizing the neurotoxic impact of MPTP in our experiments (group 1).

Non-motor manifestations of Parkinson's disease attract increasing attention since it is becoming more and more clear that their understanding can contribute to early diagnosis of this illness [44]. Such manifestations of Parkinson's disease include sleep disorders nighttime insomnia, daytime sleepiness, and REM behavior disorders, which are early predictors of Parkinson's disease that can appear years or even decades before motor disturbances [22]. The data obtained in this work demonstrate that analysis of the changes in sleep-waking cycle is an adequate approach to verify early stages of Parkinson's disease in model animals as well as to test

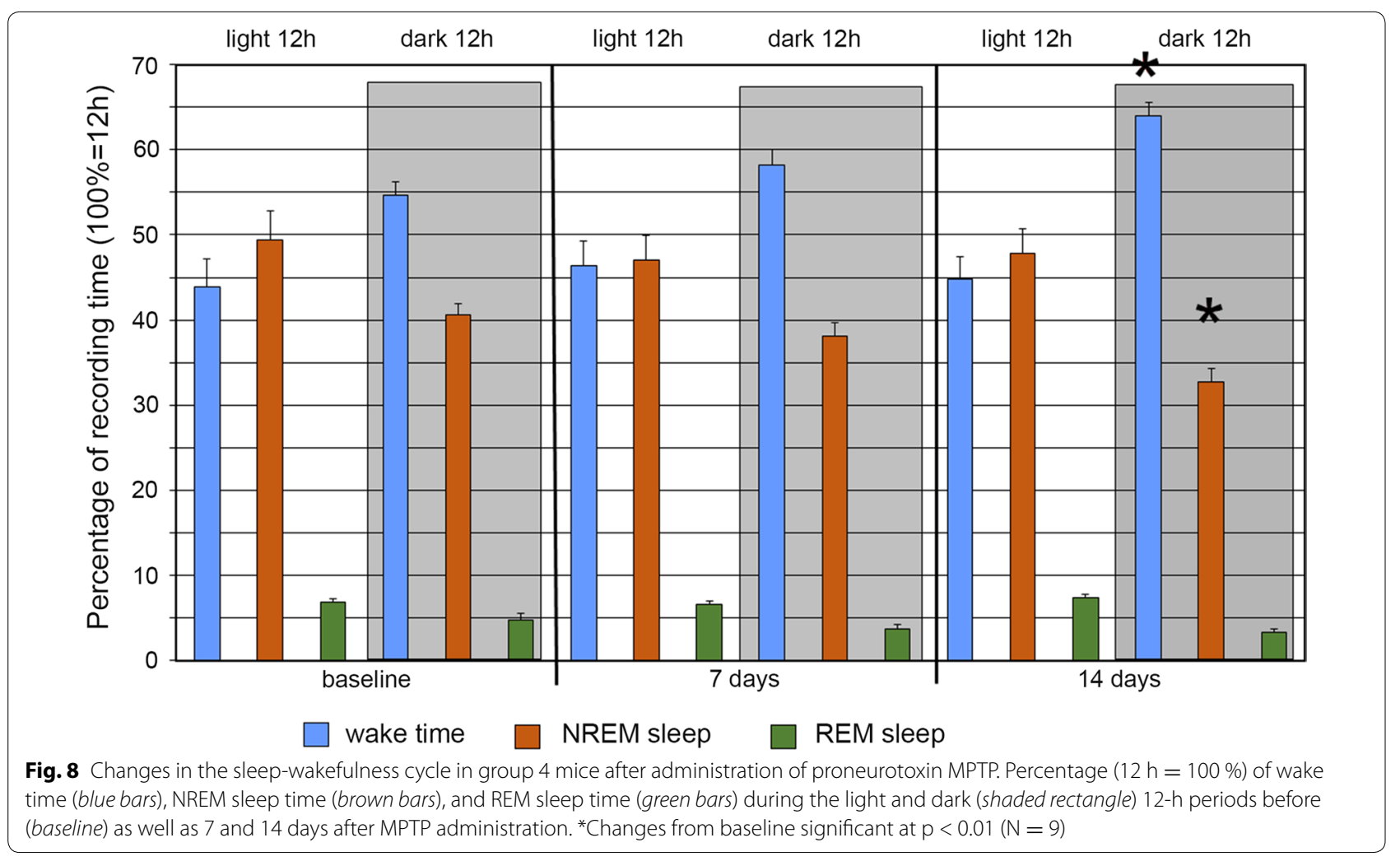



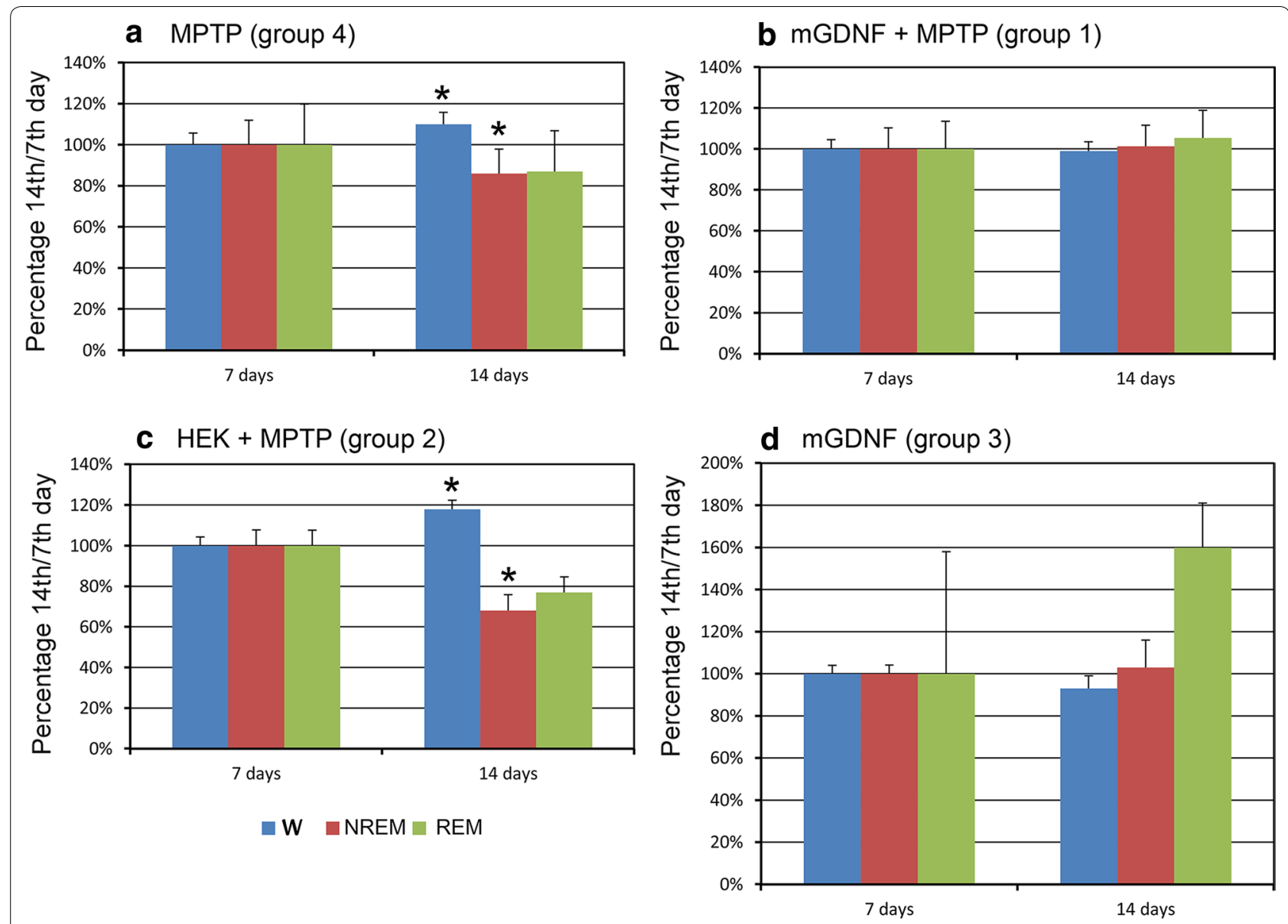

Fig. 9 Changes in sleep-wakefulness cycle at the 14th day since administration as compared to the 7th day. Proportions (normalized to day 7 after MPTP administration, $100 \%$ ) of wake time (blue bars), NREM sleep time (brown bars), and REM sleep time (green bars) during the dark 12-h period 7 and 14 days after MPTP administration. a Increased wake time and decreased NREM sleep time after MPTP administration in group $4(\mathrm{~N}=9$ );

b no changes in the sleep-wakefulness cycle in group 1 mice transplanted with HEK293/mGDNF/GFP cells prior to MPTP administration ( $N=9$ ); c changes in the sleep-wake cycle in group 2 mice transplanted with HEK293/GFP cells prior to MPTP administration; d no changes in the sleepwakefulness cycle in three mice transplanted with HEK293/mGDNF/GFP cells ( $N=3$ ), high REM sleep data dispersion is due to the low number of animals in the group. ${ }^{*}$ Changes are significant at $p<0.05$

anti-Parkinson's disease effects of various biochemical factors.

\section{Conclusions}

Thus, transplantation of transgenic cells with the GDNF gene lacking the pre- and pro-sequences can protect dopaminergic neurons in the mouse midbrain from the influence of subsequent administration of the proneurotoxin MPTP, which is confirmed by polysomnographic, behavioral (rotarod) and histochemical data. This work confirms our previous data that the product of the construct bearing the GDNF gene without the pre- and prosequences is not only released from transfected cells but also preserves the neurotrophic, differentiation, and neuroprotective properties.

\section{Abbreviations}

GDNF: glial cell line-derived neurotrophic factor; mGDNF: mature GDNF; MPTP: 1-methyl-4-phenyl-1,2,3,6-tetrahydropyridine; GFP: green fluorescent protein; TH: tyrosine hydroxylase; $\mathrm{TH}+$ : tyrosine hydroxylase immunopositive; ELISA: enzyme-linked immunosorbent assay; REM sleep: rapid eye movement sleep; NREM sleep: non-rapid eye movement sleep; EEG: electroencephalography; SNC: substantia nigra pars compacta; VTA: ventral tegmental area.

\section{Authors' contributions}

AR carried out immunohistochemical studies, participated in the design of the study and drafted the manuscript. NB participated in immunohistochemical studies and statistical analysis. LM performed electrophysiological experiments, NK carried out the immunoassays and cell transfection. PT participated in cell transfection and statistical analysis. DP made gene constructs. VK and GP jointly conceived of, and supervised, the study. All authors read and approved the final manuscript.

\section{Author details}

${ }^{1}$ Laboratory of Neurogenetic and Developmental Genetic, Institute of Gene Biology, Russian Academy of Sciences, Vavilova Str., 34/5, Moscow, Russia 
119334. ${ }^{2}$ Ltd Apto-pharm, Kolomensky Road, 13A, Moscow, Russia 115446. ${ }^{3}$ Department of Higher Nervous Activity, Faculty of Biology, M.V. Lomonosov Moscow State University, Lenin Hills d. 1, pp. 12, Moscow, Russia 119234. ${ }^{4}$ A.N. Severtsov Institute of Ecology and Evolution, Russian Academy of Sciences, 33 Leninskij Prosp., Moscow, Russia 119071. ${ }^{5}$ Present Address: A.N. Severtsov Institute of Ecology and Evolution, Russian Academy of Sciences, Moscow, Russia. ${ }^{6}$ Present Address: Research Institute of General Pathology and Pathophysiology, Russian Academy of Sciences, Moscow, Russia 125315.

\section{Acknowledgements}

Experiments were performed using the equipment of the IGB RAS facilities supported by the Ministry of Science and Education of the Russian Federation.

\section{Competing interests}

The authors declare that they have no competing interests.

\section{Availability of data and materials}

All supporting data in this work is contained within the manuscript.

\section{Ethics approval and consent to participate}

All in vivo experiments were approved by the Ethics Committee of Moscow State University.and were carried out in accordance with "The Guidelines for Manipulations with Experimental Animals" (the decree of the Presidium of the Russian Academy of Sciences of April 02, 1980, no. 12000-496), and the Guidelines for Humane Endpoints for Animals Used in Biomedical Research, Regulations for Laboratory Practice in the Russian Federation.

\section{Funding}

This work was supported by the Russian Science Foundation (14-15-00942, http://grant.rscf.ru/, GP).

Received: 2 October 2015 Accepted: 3 June 2016

Published online: 10 June 2016

\section{References}

1. Kust N, Panteleev D, Mertsalov I, Savchenko E, Rybalkina E, et al. Availability of pre- and pro-regions of transgenic gdnf affects the ability to induce axonal sprout growth. Mol Neurobiol. 2015;51(3):1195-205.

2. Beck KD, Valverde J, Alexi T. Mesencephalic dopaminergic neurons protected by GDNF from axotomy-induced degeneration in the adult brain. Nature. 1995;373(6512):339-41.

3. Lin LF, Doherty DH, Lile JD, Bektesh S, Collins F. GDNF: a glial cell linederived neurotrophic factor for midbrain dopaminergic neurons. Science. 1993:260(5111):1130-2.

4. Kearns CM, Gash DM. GDNF protects nigral dopamine neurons against 6-hydroxydopamine in vivo. Brain Res. 1995;672(1-2):104-11.

5. Sauer H, Rosenblad C, Bjorklund A. Glial cell line-derived neurotrophic factor but not transforming growth factor $\beta 3$ prevents delayed degeneration of nigral dopaminergic neurons following striatal 6-hydroxydopamine lesion. Proc Natl Acad Sci USA. 1995;92(19):8935-9.

6. Marco S, Canudas AM, Canals JM, Gavaldà N, Pérez-Navarro E, Alberch $J$. Excitatory amino acids differentially regulate the expression of GDNF, neurturin, and their receptors in the adult rat striatum. Exp Neurol. 2002;174(2):243-52.

7. Nicole O, Ali C, Docagne F, Plawinski L, Mackenzie ET, Vivien D, Buisson A. Neuroprotection mediated by glial cell line-derived neurotrophic factor: involvement of a reduction of NMDA-induced calcium influx by the mitogen-activated protein kinase pathway. J Neurosci. 2001;21(9):3024-33.

8. Tokumine J, Sugahara K, Kakinohana O, Marsala M. The spinal GDNF level is increased after transient spinal cord ischemia in the rat. Acta Neurochir Suppl. 2003;86:231-4.

9. Granholm AC, Reyland M, Albeck D, Sanders L, Gerhardt G, Hoernig G, et al. Glial cell line-derived neurotrophic factor is essential for postnatal survival of midbrain dopamine neurons. J Neurosci. 2000;20(9):3182-90.

10. Batchelor PE, Liberatore GT, Porritt MJ, Donnan GA, Howells DW. Inhibition of brain-derived neurotrophic factor and glial cell line-derived neurotrophic factor expression reduces dopaminergic sprouting in the injured striatum. Eur J Neurosci. 2000;12(10):3462-8.
11. Tomac A, Lindqvist E, Lin LF, Ogren SO, Young D, Hoffer BJ, Olson L. Protection and repair of the nigrostriatal dopaminergic system by GDNF in vivo. Nature. 1995;373(6512):335-9.

12. Cunningham LA, Su C. Astrocyte delivery of glial cell line-derived neurotrophic factor in a mouse model of Parkinson's disease. Exp Neurol. 2002;174(2):230-42.

13. Behrstock S, Ebert A, McHugh J, Vosberg S, Moore J, Schneider B, et al. Human neural progenitors deliver glial cell line-derived neurotrophic factor to parkinsonian rodents and aged primates. Gene Ther. 2006;1(13):379-88.

14. Biju K, Zhou Q, Li G, Imam SZ, Roberts JL, Morgan WW, et al. Macrophagemediated GDNF delivery protects against dopaminergic neurodegeneration: a therapeutic strategy for Parkinson's disease. Mol Ther. 2010;18(8):1536-44.

15. Haney MJ, Zhao Y, Harrison EB, Mahajan V, Ahmed S, He Z, et al. Specific transfection of inflamed brain by macrophages: a new therapeutic strategy for neurodegenerative diseases. PLOS ONE. 2013;8(4):e61852.

16. Airavaara M, Pletnikova O, Doyle ME, Zhang YE, Troncoso JC, Liu QR. Identification of novel GDNF isoforms and cis-antisense GDNFOS gene and their regulation in human middle temporal gyrus of Alzheimer disease. J Biol Chem. 2011;286(52):45093-102.

17. Lonka-Nevalaita L, Lume M, Leppanen S, Jokitalo E, Peranen J, Saarma M. Characterization of the intracellular localization, processing, and secretion of two glial cell line-derived neurotrophic factor splice isoforms. J Neurosci. 2010;30(34):11403-13.

18. Yokoyama H, Kuroiwa H, Kasahara J, Araki T. Neuropharmacological approach against MPTP (1-methyl-4-phenyl-1,2,3,6-tetrahydropyridine)induced mouse model of Parkinson's disease. Acta Neurobiol. 2011;71(2):269-80.

19. Ugrumov MV, Khaindrava VG, Kozina EA, Kucheryanu VG, Bocharov EV, Kryzhanovsky GN, et al. Modeling of presymptomatic and symptomatic stages of parkinsonism in mice. Neuroscience. 2011;181:175-88.

20. Rozas G, Guerra MJ, Labandeira-García JL. An automated rotarod method for quantitative drug-free evaluation of overall motor deficits in rat models of parkinsonism. Brain Res Protoc. 1997;2(1):75-84.

21. Schulte EC, Winkelmann J. When Parkinson's disease patients go to sleep: specific sleep disturbances related to Parkinson's disease. J Neurol. 2011;258(Suppl 2):S328-35.

22. Kovalzon VM, Zavalko IM. The neurochemistry of the sleep-wakefulness cycle and Parkinson's disease. Neurochem J. 2013;7(3):171-83.

23. Manolov Al, Dolgikh W, Ukraintseva YuV, Zavalko IM, Revishchin AV, Pavlova GV, et al. Moving activity and wakefulness-sleep cycle changes in a mouse MPTP model of Parkinson's disease. Ross Fiziol Zh Im I M Sechenova. 2014;100(11):1252-60.

24. Kovalzon VM, Ugrumov MV, Pronina TS, Dorokhov VB, Manolov Al, et al. Early stages of Parkinson's disease: comparative characteristics of sleep-waking cycle in patients and model animals. Fiziol Cheloveka. 2015;41(6):114-8.

25. GenBank. http://www.ncbi.nlm.nih.gov/nuccore/NM_000514.3. Accessed 20 May 2016.

26. Fujita K, Lazarovici P, Guroff G. Regulation of the differentiation of PC12 pheochromocytoma cells. Environ Health Perspect. 1989;80:127-42.

27. UTHSCSA ImageTool. http://compdent.uthscsa.edu/dig/itdesc.html. Accessed 20 May 2016.

28. Manolov Al, Kovalzon VM, Ukraintseva YV, Moiseenko LS, Dorokhov VB. Dependence of accuracy of automatic sleep scoring on spectral characteristics of mice EEG. J High Nerv Activ. 2015;65(4):1-6.

29. Monaca C, Laloux C, Jacquesson JM, Gelé P, Maréchal X, Bordet R, et al. Vigilance states in a parkinsonian model, the MPTP mouse. Eur J Neurosci. 2004;20(9):2474-8.

30. West MJ, Ostergaard K, Andreassen OA, Finsen B. Estimation of the number of somatostatin neurons in the striatum: an in situ hybridization study using the optical fractionator method. J Comp Neurol. 1996;370:11-22.

31. ImageJ. http://imagej.nih.gov/ij/index.html. Accessed 28 Oct 2015.

32. Gill SS, Patel NK, Hotton GR, O'Sullivan K, McCarter R, Bunnage M, et al. Direct brain infusion of glial cell line-derived neurotrophic factor in Parkinson disease. Nat Med. 2003;9(5):589-95.

33. Suter-Crazzolara C, Unsicker K. GDNF is expressed in two forms in many tissues outside the CNS. NeuroReport. 1994;5(18):2486-8.

34. Trupp M, Ryden $M$, Jornvall $H$, Funakoshi $H$, Timmusk T, Arenas $E$, et al. Peripheral expression and biological activities of GDNF, a new 
neurotrophic factor for avian and mammalian peripheral neurons. J Cell Biol. 1995;130(1):137-48.

35. Matsushita N, Fujita Y, Tanaka M, Nagatsu T, Kiuchi K. Cloning and structural organization of the gene encoding the mouse glial cell line-derived neurotrophic factor, GDNF. Gene. 1997;203(2):149-57.

36. Grimm L, Holinski-Feder E, Teodoridis J, Scheffer B, Schindelhauer D, Meitinger T, et al. Analysis of the human GDNF gene reveals an inducible promoter, three exons, a triplet repeat within the $3^{\prime}$-UTR and alternative splice products. Hum Mol Genet. 1998;7(12):1873-86.

37. Lee R, Kermani P, Teng KK, Hempstead BL. Regulation of cell survival by secreted proneurotrophins. Science. 2001:294(5548):1945-8.

38. Nykjaer A, Lee R, Teng KK, Jansen P, Madsen P, Nielsen MS, et al. Sortilin is essential for proNGF-induced neuronal cell death. Nature. 2004;427:843-8

39. Teng HK, Teng KK, Lee R, Wright S, Tevar S, Almeida RD, et al. ProBDNF induces neuronal apoptosis via activation of a receptor complex of p75NTR and sortilin. J Neurosci. 2005;25:5455-63.
40. Yano H, Torkin R, Martin LA, Chao MV, Teng KK. Proneurotrophin-3 is a neuronal apoptotic ligand: evidence for retrograde-directed cell killing. J Neurosci. 2009;29:14790-802.

41. Sun $X L$, Chen BY, Xia Y, Wang JJ, Chen LW. Functional switch from pro-neurotrophins to mature neurotrophins. Curr Protein Pept Sci. 2013;14(7):617-25.

42. Piccinini E, Kalkkinen N, Saarma M, Runeberg-Roos P. Glial cell linederived neurotrophic factor: characterization of mammalian posttranslational modifications. Ann Med. 2013;45:66-73.

43. Sun XL, Chen BY, Duan L, Xia Y, Luo ZJ, Wang JJ, et al. The proform of glia cell line-derived neurotrophic factor: a potentially biologically active protein. Mol Neurobiol. 2014;49(1):234-50.

44. Truong DD, Wolters EC. Recognition and management of Parkinson's disease during the premotor (prodromal) phase. Expert Rev Neurother. 2009;9(6):847-57.

\section{Submit your next manuscript to BioMed Central and we will help you at every step:}

- We accept pre-submission inquiries

- Our selector tool helps you to find the most relevant journal

- We provide round the clock customer support

- Convenient online submission

- Thorough peer review

- Inclusion in PubMed and all major indexing services

- Maximum visibility for your research

Submit your manuscript at www.biomedcentral.com/submit 